\title{
Comparative studies of brain evolution: a critical insight from the Ghiroptera
}

\author{
Dina K. N. Dechmann ${ }^{1,2}$ and Kamran Safi ${ }^{3 *}$ \\ ${ }^{1}$ Leibniz Institute for Zoo- and Wildlife Research, Alfred-Kowalke-Strasse 17, 10315 Berlin, Germany; \\ ${ }^{2}$ Smithsonian Tropical Research Institute, Apartado 0843-03092, Balboa, Ancon, Panama; \\ ${ }^{3}$ Institute of Zoology, Zoological Saciety of London, Regent's Park, London NW1 $4 R$, UK
}

\begin{abstract}
Comparative studies of brain size have a long history and contributed much to our understanding of the evolution and function of the brain and its parts. Recently, bats have been used increasingly as model organisms for such studies because of their large number of species, high diversity of life-history strategies, and a comparatively detailed knowledge of their neuroanatomy. Here, we draw attention to inherent problems of comparative brain size studies, highlighting limitations but also suggesting alternative approaches. We argue that the complexity and diversity of neurological tasks that the brain and its functional regions (subdivisions) must solve cannot be explained by a single or few variables representing selective pressures. Using an example we show that by adding a single relevant variable, morphological adaptation to foraging strategy, to a previous analysis a correlation between brain and testes mass disappears completely and changes entirely the interpretation of the study. Future studies should not only look for novel determinants of brain size but also include known correlates in order to add to our current knowledge. We believe that comparisons at more detailed anatomical, taxonomic, and geographical levels will continue to contribute to our understanding of the function and evolution of mammalian brains.
\end{abstract}

Key words: Chiroptera, encephalisation, expensive tissue, hippocampus, mating system, mosaic evolution, neocortex, neuroecology, niche adaptation, phylogeny.

\section{CONTENTS}

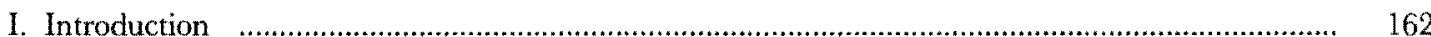

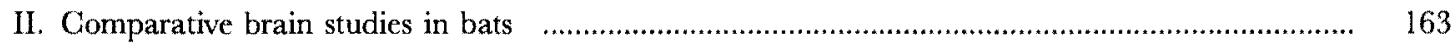

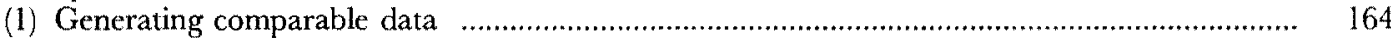

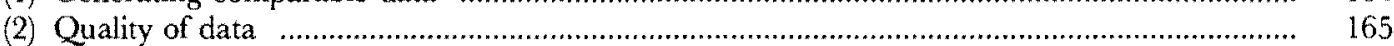

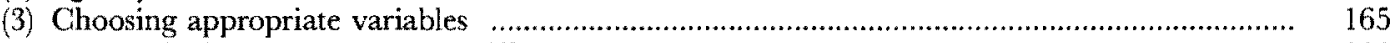

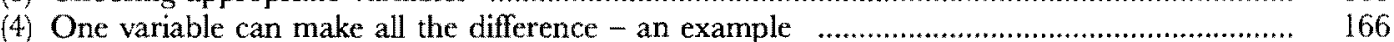

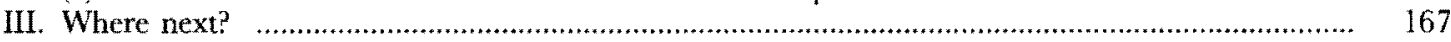

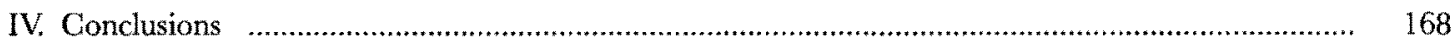

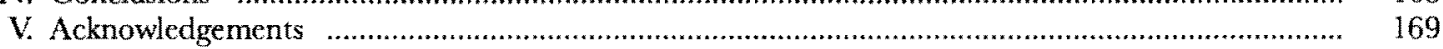

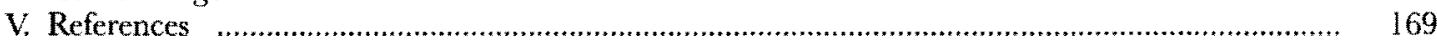

* Address for correspondence: Tel: +44(0)20 7449 6449; E-mail: kamran.safi@ioz.ac.uk 


\section{INTRODUCTION}

Intelligence, which still has to be defined satisfactorily, is usually considered to be associated with large brains; humans with their particularly large brains relative to body size have been used as 'proof' for this (Willerman et al., 1991; Witelson, Beresh \& Kigar, 2006; but see Rotha \& Dicke, 2005). The resulting interest in the evolution of brain size has produced many comparative studies investigating correlations with ecological, social, energetic and behavioural variables in various animal taxa. These correlations have made major contributions to our understanding of the evolution of the brain. Recently there has been renewed interest in this field due to the introduction of new methods for phylogenetic analyses, which estimate ancestral states and assess the most likely mode of evolution (reviewed in Healy \& Rowe, 2007). The increasing availability of ecological and behavioural data in conjunction with molecular phylogenies allows new forms of analysis. 'The quest for the determinants of brain size has historically been dominated by primatologists and anthropologists, who produced the largest body of literature and among whom there is vigorous debate (c.g. Aiello \& Wheeler, 1995; Barton, 1998, 2006; Dunbar, 1992; Fish \& Lockwood 2003; Hladik, Chivers \& Pasquet, 1999; Jerison, 1973; Lindenfors, 2005; Reader \& Laland, 2002). However comparative studies of other taxa including non-primate mammals (Baron \& Jolicoeur, 1980; Dunbar, 1998; Eisenberg \& Wilson, 1978; Lapointe, Baron \& Legendre, 1999; Pitnick, Jones \& Wilkinson, 2006; Safi \& Dechmann, 2005; Safi, Seid \& Dechmann, 2005; Schulz \& Dunbar 2006) and insects (Ehmer \& Gronenberg, 2004; Julian \& Gronenberg, 2002; Niven \& Laughlin, 2008) have also added important insights. There are two main underlying questions when comparing brain size. One is how species maintain their brain energetically, especially in light of suggested trade-offs with other energetically expensive tissues such as the digestive system, heart, testes, or maternal energy constraints (the expensive tissue hypothesis; Aiello, Bates \& Joffe, 2001; Aiello \& Wheeler, 1995; Isler \& van Schaik, 2006a, b). Second is the question why brains look and function in the way they do, i.e. which selective pressures contributed to the evolution of species' current phenotypes. Most research regarding the 'why' question has focussed on the correlation between social behaviour and neocortex size, and between diet and the size of different sensory centres of the brain involved in food acquisition, especially those responsible for vision, olfaction and spatial memory (Barton, 1996, 1998; Barton, Purvis \& Harvey, 1995; Biegler et al., 2001; Dunbar, 1992; Maguire et al., 2000).

Comparative studies of brain size have taught us a lot about why brains look the way they do by investigating correlations between ecology and behaviour, as well as energetic trade-offs and neuronal plasticity. But drawing general conclusions from such purely statistical analyses without experimental verification may be misleading. An example is Dunbar's influential work on primates (Machiavellian Intelligence Theory: Dunbar, 1992, 1998) in which he demonstrated a positive correlation between the size of the neocortex and group size. Dunbar's own subsequent analyses of similar data confirmed this for most carnivores but not all insectivores (Dunbar, 1998). Larger group size in primates implies more frequent and complex social interactions, however, this may or may not apply to other taxa (Perez-Barberia, Schultz \& Dunbar, 2007), and new evidence shows that even in primates this correlation might only be true for females (Lindenfors, 2005). Many animals such as ungulates form large aggregations, but little or no social interactions that might be connected to large neocortex size take place in those groups (Shultz \& Dunbar, 2006). Bats, too, often aggregate in large numbers due to limited availability of suitable roosts (Kunz, 1982; Lewis, 1995 ) and individuals in those colonies may not interact much or only in smaller subunits not discernible to the human observer. Social interactions may be more complex in smaller groups that depend on individual recognition to ensure limitation of group size and prevent cheating. In bats, brain size increases in species with small roosting associations and singly mating females and males in more complex social systems such as harems have a larger neocortex (Pitnick et al, 2006).

Another example of a brain region that has received much attention in comparative studies is the hippocampus. Similar to the inconsistencies found in the relationship between neocortex size and social interactions, correlations between hippocampus size and a main function, spatial memory, have produced contradicting results. For example, Krebs $t$ al. (1989) found a positive correlation in passerines, whereas lwaniuk \& Nelson (2001) found no correlation in waterfowl. However, knowledge on the detailed function of the hippocampus and other brain regions is incomplete and may vary among taxa. An example of potentially fundamental differences among taxa in the basic organisation, and thus possibly the function, of the hippocampus is the low to absent rates of neurogenesis in the hippocampus of bats (Amrein, et al., 2007), similar to the situation in primates but in great contrast to the high neurogenesis rates recorded in the hippocampi of rodents.

Lack of detailed knowledge often makes it difficult to identify the appropriate brain region when looking at the influence of a potential selective pressure. Many studies have correlated the size of energetically expensive tissue with brain size (Aiello \& Wheeler, 1995; Isler \& van Schaik, $2006 a, b$; Jones \& MacLarnon, 2004; Niven, Anderson \& Laughlin, 2007). But even though the cost of signalling in the brain has been assessed for various taxa (Attwell \& Laughlin, 2001; Laughlin, van Steveninck \& Anderson, 1998; Niven et al., 2007; Niven, Vahasoyrinki \& Juusola, 2003), how relevant these costs are for animals' energy budgets has rarely been investigated (but see Nilsson, 1996) and must be assessed before testing for trade-offs (Harvey $\&$ Krebs, 1990). For example, some primates allocate large proportions of their daily energy budget to their brains (9-20\%), but most mammals do not (approximately $5 \%$; Martin, 1981). Nonetheless, the assumption that brains are metabolically expensive is often used as a basis for the interpretation of results (e.g. Isler \& van Schaik, 2006a; Jones \& Maclarnon, 2004; Safi et al., 2005), although it 
may not be appropriate for the animal taxa in question (but see Isler \& van Schaik, 2006b). Even if the tissues in question are metabolically expensive, other factors may be more important for controlling their size and they may not be at their energetic size limit. Important here, too, is that energy consumption is commonly measured via basal metabolic rate, i.e. energy consumption while the animal is resting. However, field metabolic rates may be more appropriate, although they are more difficult to measure. In summary, many questions regarding how and why brains evolved in a particular way remain unresolved. The fairly extensive anatomical data available on bats' brains (Baron et al., 1996) have allowed their use in phylogenetic comparative studies during recent years addressing both the 'how' and the 'why' questions (Fig. 1).

\section{COMPARATIVE BRAIN STUDIES IN BATS}

Bats are an excellent model system for comparative brain size studies. They are the second largest order of mammals, are geographically widely distributed and the diversity of both their behaviour and ecology is high. Background knowledge on the sensory ecology of bats and their morphological adaptations to llight offers the potential to describe their foraging ecology fairly accurately, even if actual field observations of each species are unavailable (Fenton \& Bogdanowicz, 2002; Saunders \& Barcaly, 1992; Schnitzler, Moss \& Denzinger, 2003; Siemers \& Schnitzler, 2004). Bats, are expected to be under strong energetic selection due to their costly mode of locomotion in conjunction with their small body size, large relative surface area and thus heat loss, and high metabolic rate (Hosken \& Withers, 1997; McNab, 1969; Racey \& Speakman, 1987; but see Voigt \& Winter, 1999; Winter, 1998). A trade-off between brain size and other expensive tissues is expected, with brain size fierce energetic constraints (Jones \& MacLarnon, 2004; Pitnick et al, 2006). Availability of brain data for many species (Baron et al., 1996), good descriptions of their ecological niches, and strong predicted selection pressures on size and function make bats an interesting group for comparative brain studies.

Accordingly, comparative studies of bat neuroanatomy have a long history and have made a major contribution to the field (see Healy $\&$ Rowe, 2007 , for a recent review). Pirlot $\&$ Stephan (1970) and later Eisenberg \& Wilson (1978) found correlations between brain mass/volume and diet, categorising bats according to family as a first approximation to phylogenetic correction. They found that phytophagous bats, feeding on fruits, nectar and to a lesser extent leaves and pollen, had larger brains than animalivorous bats feeding on arthropods, vertebrates or blood. Comparisons with other animal taxa helped to identify important functional brain centres and their adaptation to the ecological niches of bats (Barton et al., 1995), showing for example that the large brains of phytophagous bats were at least partially due to increased hippocampus size and thus presumably improved spatial memory (de Winter \& Oxnard, 2001).

Soon after these initial studies comparative neuroanatomical work contributed to the belief that Chiroptera was

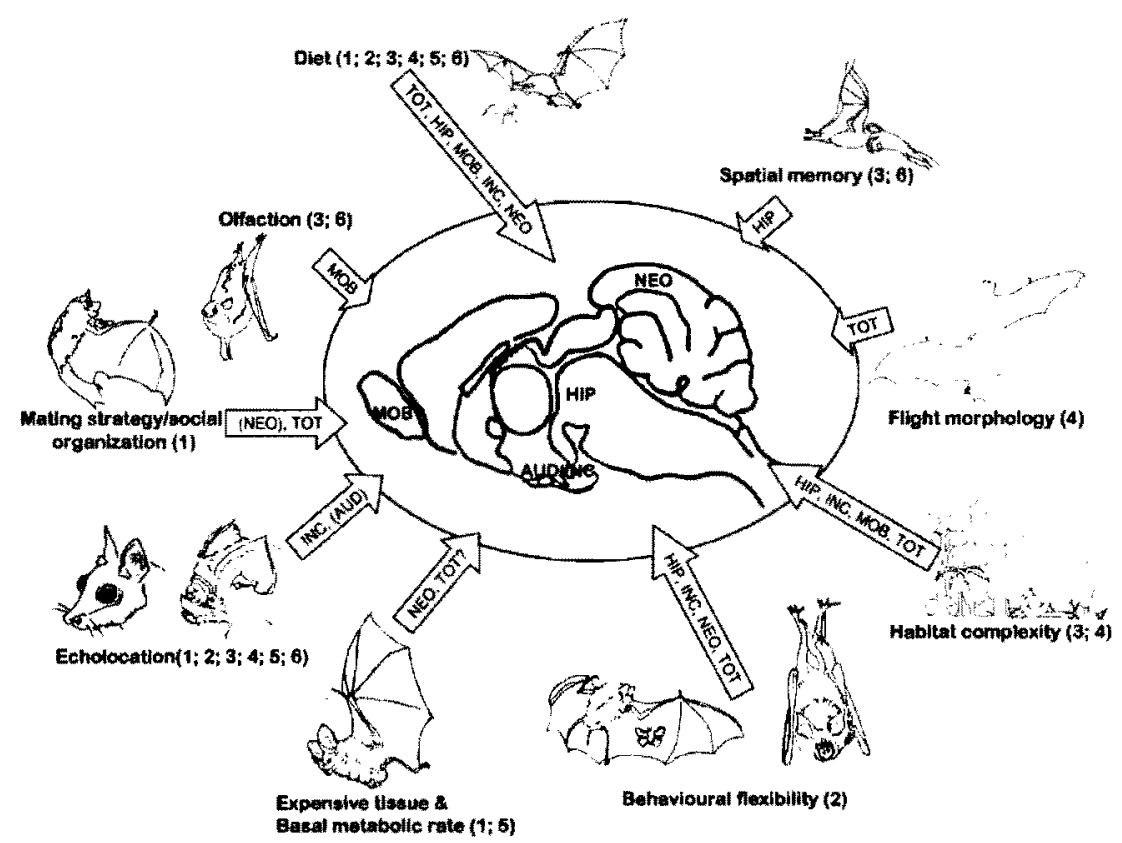

Fig. 1. Variables included in some of the most recently published analyses of comparative brain size studies in bats. Abbreviations with the arrows indicate relative size or mass of brain regions that were correlated with different ecological predictors, whereby the parentheses indicate non-significant correlations. Brain regions: TOT $=$ total brain, HIP $=$ hippocampus, NEO $=$ neocortex, $\mathrm{MOB}=$ main olfactory bulb, INC = inferior colliculus, AUD = auditory nuclei. References: 1, Pitnick et al. (2006); 2, Ratcliffe $e t$ al. (2006); 3, Safi \& Dechmann (2005); 4, Safi et al. (2005); 5, Jones \& Maclarnon (2004); 6, Hutcheon et al. (2002). 
paraphyletic with two (now abolished) suborders Mega- and Microchiroptera derived from different ancestors (Pettigrew, 1986; Pettigrew et al., 1989; Pettigrew \& Kirsch, 1998). It took almost a decade and the development of molecular phylogenies to establish that the brain is directly exposed to selective envirommental pressures, making possible neuroanatomical convergences such as a primate-like large visual and olfactory brain regions in the Megachiroptera (family Pteropodidae); a single origin for bats was thus reconsidered (Kirsch et al., 1995; Lapointe et al., 1999; Mindell, Dick \& Baker, 1991; Stanhope et al., 1992; Teeling et al., 2000; Thewissen \& Babcock, 1991). This triggered extensive discussions about the mode of brain size evolution and the role of energetic limitations and trade-offs of brain size in mosaic, i.e. independent, evolution of the size of the brain and its parts at least below the level of order (Barton \& Harvey, 2000; Brown, 2001; de Winter \& Oxnard, 2001; Safi t al, 2005; but see Finlay \& Darlington, 1995).

The diets of bats vary greatly, ranging from frugivory to carnivory or omnivory but also comprising a multitude of specialists, such as the three species of sanguivorous vampires. It is now evident that even though phytophagous bats have larger brains (Barton et al, 1995; Hutcheon, Kirsch \& Garland, 2002), significant correlations between many variables and brain size stem from effects in animalivorous species only (Pitnick et al., 2006; Safi \& Dechmann, 2005). Human data led to an assumption that the evolution of larger brains only became possible with a richer diet -the expensive tissue hypothesis- (Aiello \& Wheeler, 1995; Harvey, Clutton-Brock \& Mace, 1980) and this was reinforced by evidence from various taxa, such as primates (Fish \& Lockwood, 2003; Harvey et al, 1980; Taylor \& van Schaik, 2007). By contrast, in bats the correlation between diet quality, measured as the inverse of intestine length, and brain size is negative Jones \& Maclarnon, 2004). Due to a scattered and seasonal food availability and cluttered foraging habitat (inside vegetation), phytophagous bats with a lower quality diet face much greater sensory challenges, resulting in a larger brain than in animalivorous bats and contradicting the expensive-tissue hypothesis (Jones \& MacLarnon, 2004; Safi \& Dechmann, 2005). Taking examples from bats in the following review we identify recurring problems with and advantages of comparative brain size analyses.

\section{(1) Generating comparable data}

Bats can vary up to a hundredfold in body size (Nowak, 1994) and brain size comparisons across species require allometric correction. However, the most appropriate measures to correct for size differences, are far from resolved (Deaner et al., 2007). In bird, rodent and primate studies, the correcting factor is often remainder brain size or another part of the brain (Barton, 1999; Clark, Mitra \& Wang, 2001; Day, Westcott \& Olster, 2005; Dunbar, 1995, 1998; Jacobs et al., 1990; Joffe \& Dunbar, 1997; Pravosudov, Lavenex \& Clayton, 2002). The logic behind this is that most researchers were interested in the proportion of the brain allocated to the forebrain (the equivalent of the mammalian neocortex) and assumed that there is a maximum possible brain size and that neocortex/forebrain size did not evolve independently (Dunbar, 1998). However, the evidence is accumulating that selection acts on individual functional brain units (mosaic brain evolution) at least at higher taxonomic levels (Barton \& Harvey, 2000; Iwaniuk, Dean \& Nelson, 2004; Striedter, 2005). In addition, combinations of changes either in the investigated brain region or in the remainder of the brain could lead to a false correlation if they were caused by different evolutionary pressures. Researchers wanting to distinguish between phylogenetic and naturally selected components influencing the size of a particular brain region should thus use morphological measures, as independent as possible from the explanatory variables and from the brain region used.

From a stepwise analysis of the relationship between body size and brain size in bats shown in Fig. 2 it becomes clear that most variation in the latter can be explained by variation in body size (allometric relationship). The explanatory power can be increased by including a phylogenetic correction both for all bats or for separate analyses of phytophagous and animalivorous species (as classified by Jones and MacLarnon, 2004). The phylogenetic correction was made in the regression models using phylogentic Eigenvector regression (Diniz-Filho, De Sat'ana \& Bini, 1998), where the principal coordinates explained $99 \%$ of the original phylogenetic relationship in the chiropteran supertree (Jones, Bininda-Edmonds \& Gittleman, 2005; Jones et al., 2002). A small component remains that is unexplained by the allometric relationship. These residuals are ultimately the object of most comparative studies of brain size. They can be explained by direct natural selection since the last speciation event [s-component sensu Desdevises et al. (2003) included in 'unexplained' in Fig. 2],

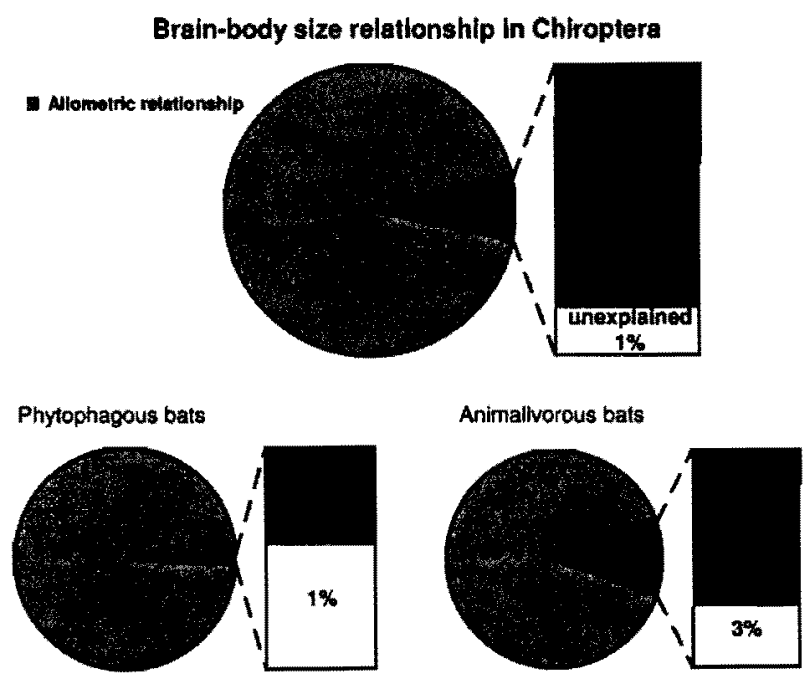

Fig. 2. Amount of variance in brain mass explained by the allometric relationship with body mass alone and by including a phylogenetic correction (see text) for all bats (upper pancl) or for phytophagous and animalivorous bats separately (lower panels). 
phylogenetic niche conservatism and non-adaptive phylogenetic constraints [p-component sensu Desdevises et al. (2003) included in 'phylogeny' in Fig. 2] and an error term of the regression models (also included in 'unexpained' in Fig. 2). Note that the allometric analysis of Fig. 2 indicates that there is more variation in brain size to be explained in animalivorous than in phytophagous bats, perhaps explaining why more brain size correlations were found for animalivorous bats in previous studies (Pitnick et al., 2006; Safi \& Dechmann, 2005). As a further caution, individual studies often compare the size of parts of the brain as well as total brain size with the correlated variable (Pitnick et al., 2006), resulting in the need for a universal controlling variable. Body mass is the most easily available and most commonly used measure to correct for allometric relationships. However, it has been argued that body mass may be too variable even within individuals to be reliable and should be used with caution especially when sample sizes are small (Harvey \& Krebs, 1990).

Phylogenetically corrected analyses have been used extensively to investigate how brain size evolves. Nonetheless, whether to apply phylogenetic correction remains controversial (Barraclough, Vogler \& Harvey, 1998; DiazUriarte \& Garland, 1996; Freckleton, Harvey \& Pagel, 2002; Martin, Genoud \& Hemelrijk, 2005; Martins \& Hansen, 1999; McNab, 2003; Pagel, 1994, 1999a). Very simply put, a phylogenetically corrected analysis tests how a certain trait evolved within a taxonomic group. The phylogenetic correction takes into account that the species being compared share a common history and do not represent independent data points (Harvey \& Pagel, 1991). A species-level analysis compares the current state of a trait but ignores variation in the number and taxonomic proximity of species (Felsenstein, 1985). Authors of early studies simply plotted brain sizes of bats and/or other taxa against body mass and then discussed where, in relation to the regression line, the various subgroups clustered in the context of diet or other variables (e.g. Eisenberg \& Wilson, 1978; Lapointe et al., 1999). A similar approach was applied recently by de Winter \& Oxnard (2001), who used a complex cluster analysis and a larger number of brain parameters to look for patterns within and among orders of mammals without a prior hypothesis in mind. Methods to test whether a phylogenetic correction is appropriate or even necessary do exist (Gittleman \& Kot, 1990; Pagel, $1997,1999 a, 1999 b)$ but most authors present results of both a phylogenetically corrected and species-level analysis (Garland, Harvey \& Ives, 1992). One problem with phylogenetically corrected analyses of bat data is that the quality and resolution of the tree used may influence the results (Symonds, 2002; Symonds \& Elgar, 2002). However, Jones \& MacLarnon (2004), aware of this potential problem analysed their data using two different trees, and did not obtain substantially different outcomes (see also reanalysis of the data of Pitnick et al., 2006 in Section II.4 below).

\section{(2) Quality of data}

The comparative analysis of large data sets is attractive, because it allows identification of patterns at broad taxonomic and evolutionary scales. However, there can also be inherent problems with the quality and source of data (Aiello et al., 2001). In brain studies, for example, it is important to know how the brain parameters were measured because the method may significantly influence the resulting values (see Healy \& Rowe, 2007 for a review). To date, almost all bat brain data have been taken from Baron et al. (1996), who collected brains using a consistent methodology, but authors of future studies should bear the influence of data collection method in mind when pooling new with literature data. Also, published data should be used with caution, as they may contain errors or methodological weaknesses. Examples are misclassifications of diet (e.g. 'fruit-eating' Trachops cirrhosus, Tonatia bidens, and Vampyrum spectrum in Hutcheon et al., 2002), foraging mode (e.g. 'aerial foraging' Myotis myotis in Hutcheon et al., 2002, or Thyroptera tricolor in Kalko, Handley \& Handley, 1996), or size (Vespertilio murinus given as twice their actual mass in Baron et al., 1996). In some studies (including Baron et al., 1996) sample sizes are small (see also Lindenfors, Nunn \& Barton, 2007 for the effect of small datasets), seasonal and regional effects are ignored, and subsequent taxonomic reorganisation is not always easy to integrate. Finally, and importantly, data are often combined for the sexes.

If sexual selection acts on brain size as with other morphological traits, one would expect sex-specific differences in the size of the brain or its parts. In passerine birds, males of species that produce complex songs and exhibit less extra-pair matings have larger overall brain size (Garamszegi et al., 2005a, b). In bower birds seemingly more complex bowers tend to be built by larger brained males (Madden, 2001). In voles (Jacobs et al., 1990) and brood parasitic cowbirds (Reboreda, Clayton \& Kecelnik, 1996; Sherry et al., 1993), the sex with higher demands on spatial abilities has a larger hippocampus. However, sex-specific data for brain size are lacking for many taxa including primates (Lindenfors, 2005; Lindenfors et al., 2007) and bats (Pitnick et al., 2006), despite their relevance; for example, when testing the effect of mating system and testes size (Pitnick et al., 2006) or the trade-off between maternal investment and brain size (Jones \& MacLarnon, 2004).

Finally, in all comparative studies, a bias is introduced by previous research effort and the selection of species (Ackerly, 2000). 'This may apply particularly to literature concerning unusual and interesting behaviours such as innovation in birds (discussed in Sherry et al., 1993) or behavioural flexibility in bats (Ratcliffe, Fenton \& Shettleworth, 2006). The true frequency and extent of these 'charismatic' behaviours are often difficult to determine, because the absence of a published observation does not prove absence of the ability to express a behaviour. For example evidence of social learning of a novel behaviour by adults based on observation of a conspecific has been reported in bats (Page \& Ryan, 2006; Ratcliffe \& ter Hofstede, 2005), but there are few experimental studies on this to date.

\section{(3) Choosing appropriate variables}

Comparative studies can be useful in identifying potentially relevant neuronal structures. Even the lack of a correlation 
can, with sufficient statistical power, provide useful information helping to exclude hypotheses and restrict the potential functions associated with brain regions. For example, in bower birds, bower complexity was not correlated with forebrain size (and thus with behavioural complexity; Madden, 2001) but with the size of the cerebellum (involved in motor learning; Day et al., 2005). Shultz tt al. (2005) were able to show that the size of the telencephalon was a better predictor for problem-solving abilities than total brain size in migratory birds. Identifying and testing the correct brain area responsible for the behaviour in question is obviously important (see also Section II.4). In bats, correlation between foraging niche, exemplified by wing area, and the size of an important centre for the processing of auditory information, the inferior colliculus (Safi \& Dechmann, 2005) was more satisfactory than a previous attempt using the size of the auditory nuclei, a poorly understood aggregate of brain modules (Hutcheon et al, 2002). The problem of choosing the right brain region has been discussed for a broader range of taxa by Healy \& Rowe (2007).

Not only is it difficult to select an appropriate brain region associated with a behaviour but it may also be difficult to find an appropriate variable with which to test the hypothesis. For example several authors used diet to determine the influence of bat species' ecological niche on the size of various brain regions (Hutcheon et al., 2002; Pitnick et al., 2006; Safi \& Dechmann, 2005; Safi et al., 2005). However, spatial memory and thus hippocampus size may be much more challenged by the complexity of the foraging habitat, than by features of its prey (Abbott $e t a l$, 1999). Foraging habitat would be represented better by continuous variables of wing morphology than by discretely categorised diet (Safi \& Dechmann, 2005). How much we still need to learn about the function of brain regions and the mechanisms influencing brain morphology is highlighted by a study of adult neurogenesis rates in the hippocampus of bats (Amrein et al, 2007). In rodents and birds, highly developed spatial abilities are correlated with higher numbers of establishing neurons. Consequently, Amrein et al. (2007) expected to find high adult neurogenesis rates, correlated with home range size and/or habitat complexity, in three-dimensionally manoeuvring bats. By contrast, adult neurogenesis was low or absent in all bat species investigated.

In an attempt to avoid choosing the wrong variable, authors often include multiple variables when screening for potential functional relationships. This is theoretically a good approach, but can generate statistic problems such as cross-correlations among variables and an higher probability of type I error due to a large number of variables and limited data sets. In addition, such an approach is constrained by the availability of data: brain size data may be available for one subset of species, gut length for another, and wing shape for a third, with very little overlap among them (Jones \& MacLarnon, 2004).

\section{(4) One variable can make all the difference - an example}

The importance of the proper selection of variables and their potential influence on the outcome of comparative studies is best shown using a recent example. An innovative recent paper (Pitnick et al. 2006) tested the influence of sexual selection on the evolution of brain and neocortex size. Pitnick et al. (2006) correlated the relative size of the total brain and the neocortex with variables related to mating strategy, including testes size. Species with promiscuous fermales had smaller brains and neocortices than species with female mate fidelity. As there was a significant negative correlation between testes and total brain size but not between neocortex size and testes size, the authors concluded that there was an energetic trade-off between the sizes of two expensive tissues: the brain and the testes.

In the following we show the results of a reanalysis of a subset of these data to demonstrate the effects of the selection of samples and covariates (lable 1). The type of mating system is expected to co-vary with foraging ecology (Emlen \& Oring, 1977), which in turn is correlated with brain size (Safi et al., 2005). Thus, in an additional analysis, we included wing area, as a measure of foraging strategy, from Norberg \& Rayner (1987) using the same phylogenies as Pitnick et al. (2006). All our analyses were done both at species level and phylogenetically corrected using phylogenetic generalised least-squares (PGLS: Pagel, 1994, 1997, $1999 a$ ) in R 2.7.0 using the packages 'geiger' and 'ape' (R Development Core Team, 2008). Since the outcome of the tests did not change qualitatively between the different versions of the chiropteran supertrees we mainly report on the results of only one (treel in Pitnick et al., 2006). The data and the analysis script used in $\mathrm{R}$ can be obtained from the authors upon request.

Table 1. Lincar model of residual testes mass and residual wing arca as correlates of residual total brain mass of animalivorous bats $(\mathbf{N}=38$ ) at species level and after phylogenetic generalised least-squares (PGLS) correction using two different phylogenetic trees. Residual wing area is positively correlated with total brain smass, but residual testes mass is not

\begin{tabular}{|c|c|c|c|c|c|c|c|c|c|}
\hline & \multicolumn{9}{|c|}{ Total brain mass } \\
\hline & \multicolumn{3}{|l|}{ species level } & \multicolumn{3}{|l|}{ PGLS (ireel) } & \multicolumn{3}{|l|}{ PGLS (tree2) } \\
\hline & estimate $\pm \mathrm{sd}$ & $\mathrm{t}$ & $\mathrm{p}$ & estimate $\pm \mathrm{sd}$ & $\mathrm{t}$ & $\mathrm{p}$ & cstimate $\pm s d$ & $\mathrm{t}$ & $\mathrm{p}$ \\
\hline Intercept & $-0.15 \pm 0.03$ & -5.9 & $<0.0001$ & $-0.11 \pm 0.08$ & -1.5 & 0.15 & $-0.11 \pm 0.07$ & -1.5 & 0.15 \\
\hline Residual testes mass & $-0.07 \pm 0.04$ & -1.8 & 0.08 & $-0.01 \pm 0.03$ & -0.4 & 0.68 & $-0.01 \pm 0.03$ & -0.3 & 0.74 \\
\hline Residual wing area & $0.99 \pm 0.29$ & 3.4 & 0.002 & $1.16 \pm 0.19$ & 6.2 & $<0.001$ & $1.17 \pm 0.18$ & 6.4 & $<0.001$ \\
\hline
\end{tabular}


Nearly all the variation in residual bat brain mass (mg) stems from animalivorous species (Fig. 2). In addition, all animalivorous bats use echolocation, whereas phytophagous bats contain the echolocating bats of the family Phyllostomidae as well as the flying foxes (Pteropodidae), which do not use laryngeal echolocation. We reanalysed the animalivorous species in the Pitnick et al. (2006) data set correlating residual total brain size (from a least-squares regression of log body mass against log brain mass) with residual testes size (from a least squares regression of log body mass against log testes mass). For each of the logconverted predicted variables (total brain size, testes mass and wing area) we used log-converted body mass values from the appropriate source as the predictor. In addition we excluded the following statistical outliers, which significantly influenced the linear regression models: Hipposideros commersoni (outlier in residual brain mass), Rhinopoma microphyllum (outlier in residual testes mass), Desmodus rotundus (outlier in residual neocortex size), and Tylonycteris pachypus (outlier in residual hippocampus size).

Our reanalysis of the Pitnick et al. (2006) bivariate regression of residual brain mass against residual testes mass at the species level with the adjusted data set confirmed a significant negative correlation between these two traits (Fig. 3: slope $=-0.14 \pm 0.03, F_{1,46}=16.0, P=0.0002$ ). This remained true after phylogenetic correction (treel: slope $=-0.14 \pm 0.04, t=-3.6, P=0.0007$. tree2: slope $=-0.13 \pm 0.04, t=-3.3, P=0.002$ ).

As concluded by Pitnick et al. (2006) the negative correlation between residual brain and testes mass seemed to indicate a trade-off between two expensive tissues. However, after including residual wing area, both residual total brain and neocortex mass (data not shown) were no longer correlated with residual testes mass (Table l). By contrast, relative wing area remained a good explanatory variable of relative brain size (Table 1 ).

Consequently, the expensive tissue hypothesis, i.e. that an energetic trade-off exists between testes size and total brain

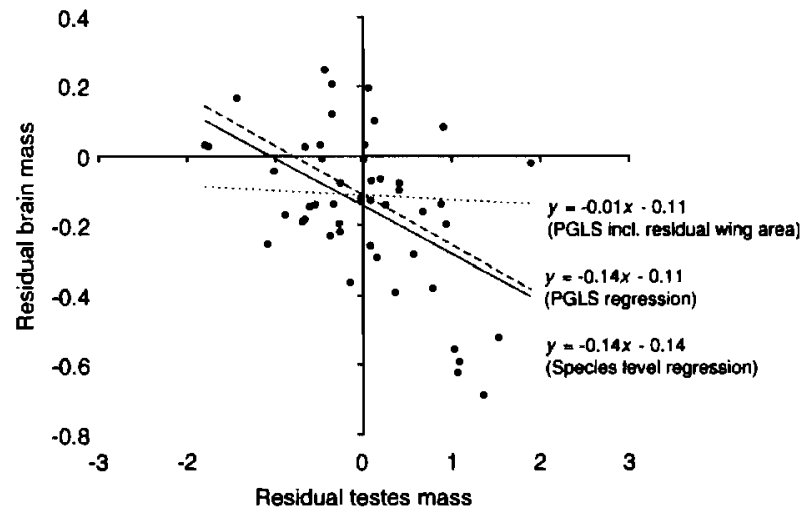

Fig. 3. Regression of residual testes mass against residual total brain mass at the species level (scatterplot and solid line), after phylogenetic correction (dashed line) and after including residual wing arca in the model (dotted line). For significance levels of the regressions see Table 2. PGLS, phylogenetic generalised least-squares. size no longer explained the results. The important message of our reanalysis is not so much the absence of a trade-off between relative brain size and testes mass, but the powerful effects of including a known predictor of brain size (Table 2). In addition, selection of a subset of species, the animalivorous bats, known to be responsible for variation in brain size, led to a pronounced decrease from -0.08 to -0.14 in the slopes of the regression (Table 2).

\section{WHERE NEXT?}

The example given above (Section II.4) highlights several points of interest: First, interpretation of correlative data although conducted on a large set of species and with the appropriate statistical methods, requires cautious planning, interpretation, and consideration. Second, we show the necessity of integrating established knowledge. We cannot expect to understand brain evolution by correlating single effects with total brain size.

Although this is a recurring issue in correlative work, it is still uncommon for previous findings to be included in tests of new hypothesis. A likely explanation is that authors are tempted to treat their results as fact rather than as correlations. Comparative analysis methods allow us to generate testable hypotheses about the relationship between the brain or its parts and possible factors shaping and constraining them. One should ask whether new results remain robust in the light of what already has been found and how these factors interact with each other to determine the neuroecology of the species in focus. Of course this will require filling gaps in the data sets and producing unified data bases. The fact that almost all authors publish their original data is a first step in this direction (Jones \& MacLarnon, 2004; Pitnick et al., 2006; Safi et al., 2005).

So, to return to our original questions, how and why are bat brains as large as they are and can we distinguish between these two question. It has been assumed that flight in bats is energetically expensive, yet a comparative study shows that at least hovering flight is more efficient in bats than in hummingbirds (Voigt \& Winter, 1999; Winter, 1998) and consequently bat flight although more costly than terrestrial locomotion, may be more efficient than previously thought. Several studies have searched for evidence of an energetic trade-off between brain size and metabolic costs in bats. However, either no such negative correlation was found for either metabolic rate, (Jones \& MacLarnon, 2004; McNab \& Eisenberg, 1989) or gut length (Jones \& MacLarnon, 2004), or an alternative explanation was given (e.g. present study). There is little firm evidence that the brains of bats are as energetically limiting and limited as those of some primates and trade-offs between the brain and other expensive tissues and/or behaviours may not be as important in shaping the brain as other selective pressures.

The factors determining and limiting brain size are still only partially understood. For example, it remains intriguing that although the brains of phytophagous bats are on average larger, size variation is greater in animalivorous bats. One explanation is that there is much less variation in 
Table 2. Stepwise demonstration of the effect of our reanalysis of the original data of Pitnick et al. (2006). Pitnick et al.'s results, our results including animalivorous bats only, and our results adding wing area (foraging ecology) on the correlation of residual testes mass (mating system) with I. residual brain mass and II. residual neocortex volume. Slopes and significance levels refer to the phylogenetically corrected analyses (trcel)

\begin{tabular}{|c|c|c|c|c|c|c|c|c|}
\hline \multirow{2}{*}{$\begin{array}{l}\text { Corrclation of } \\
\text { residual log- } \\
\text { converted testes } \\
\text { mass with: }\end{array}$} & \multicolumn{2}{|c|}{ Pitnick el al. (2006) } & \multirow[b]{2}{*}{$\Rightarrow$} & \multicolumn{2}{|c|}{ This study } & \multirow[b]{2}{*}{$\Rightarrow$} & \multicolumn{2}{|c|}{ This study } \\
\hline & Slope & $P$ & & Slope & $P$ & & Slope & $P$ \\
\hline $\begin{array}{l}\text { I. Total brain mass } \\
\text { II. Neocortex mass }\end{array}$ & $\begin{array}{l}-0.08 \\
-0.06\end{array}$ & $\begin{array}{l}0.02 \\
\text { NS }\end{array}$ & $\begin{array}{l}\text { restricted data to } \\
\text { animal-cating bats }\end{array}$ & $\begin{array}{l}-0.14 \\
-0.06\end{array}$ & $\begin{array}{l}<0.001 \\
\mathrm{NS}\end{array}$ & $\begin{array}{l}\text { corrected for } \\
\quad \text { foraging ecology }\end{array}$ & $\begin{array}{l}-0.01 \\
-0.03\end{array}$ & $\begin{array}{l}\text { NS } \\
\text { NS }\end{array}$ \\
\hline
\end{tabular}

the foraging strategies of frugivores, whose food is always attached to plants and thus associated with more or less similarly dense habitats (Safi \& Dechmann, 2005). Yet, recent evidence shows that the diet of many frugivorous and nectarivorous species also contains some insects, a topic which urgently warrants further investigation (Herrera et al., 2002). One testable hypothesis could be that relative brain size increases with increasing proportion of plant material in the diet leading to the observed difference between phytophagous and animalivorous bats, which is in strong contrast to the situation in carnivores and primates (Aiello \& Wheeler, 1995; Fish \& Lockwood, 2003; Harvey et al., 1980). Yet, we lack sufficiently detailed knowledge on most bats' diet to test this hypothesis.

In summary, we currently face a situation where a variety of brain size parameters have been correlated with a variety of variables (Fig. l), most of which are correlated with each other, opening up possibilities for more detailed analyses. We suggest that it is important to verify results from correlative studies by detailed investigation of carefully selected species, looking for differences among closely related species, intraspecific variation, or sex differences. As bats are longlived, slowly reproducing organisms with many species threatened by extinction, collection of large numbers of brains is now questionable and newly available methods should be tested for their applicability. For example the structure of the inferior and superior colliculus in bats of various sizes has been successfully determined in vivo with the aid of magnetic resonance imaging ( $\mathrm{Hu}$ et al., 2006). Other advances may help to determine the function of brain regions. In Eptesicus fuscus, one of the best-studied bat species worldwide, a four-tetrode implant was used to quantify hippocampal activity patterns in bats moving freely in an arena; this method confirmed the existence of place cells in the bat hippocampus (Ulanovsky \& Moss, 2007).

The establishment of a global data base in which measures of brain size as well as other morphological and ecological variables are freely available could be a starting point for ensuring that previous results are integrated into future studies. Currently ecological and morphological data bases are being established for other groups to support research on macroecological and macroevolutionary scales. PanTHERIA (Jones $e t$ al., in press) is one such data base for mammals, which could easily be expanded to incorporate neuroanatomical data.

When asking how and why large brains evolved, we ultimately seek to understand our own evolutionary past.
However, how many more meaningful answers can be gleaned from comparative studies based on current knowledge and data is questionable. The current evidence suggests that the brain of mammals is organised into functional modules on which evolution acts independently. In addition, brain size evolution is not directional; brains do not consistently become larger over the course of evolution (Brown et al., 2004; Niven, 2005, 2007; Safi et al., 2005; Striedter, 2005; Taylor \& van Schaik, 2007). Instead of looking at large complex structures with more comparative studies, the focus should shift to small functionally distinct brain regions. Their higher specificity will allow us to derive more precise answers from comparative studies and to generate more robust hypotheses about the relationships between ecology and neurobiology. Here bats could contribute fundamentally. In addition bats' brains have apparent similarities to those of primates making them an interesting potential model system, perhaps more suitable than the widely used rodent models. One example is the regression of the dorsal cochlear nucleus in bats, and other long-lived animals such as cetaceans and primates including man (Baron et al., 1996). Another, is the large visual and olfactory brain centres in pteropodid bats that led to the temporary belief that they had a common origin with primates. Finally, recent studies have revealed that adult neurogenesis as well as cellular and network activity in the bat hippocampus is more similar to that of primates than to rodents (Amrein et al., 2007; Baron et al., 1996; Ulanovsky \& Moss, 2007). Convergences in morphology, neurogenesis and cell activity between chiropterans and primates could yield important insights into brain functioning and processes underlying brain development.

\section{CONCLUSIONS}

(1) Studies of neuroecology have shed light on how environmental and ecological adaptations influence brain size and brain function. Two fundamental questions have been addressed: how the metabolic demands of large brains are met and why brains look the way they do. These studies ultimately try to understand the mechanisms which select for enlarged brain sizes and aim to clarify our own evolutionary history.

(2) Although many studies have been conducted, the entire field remains highly heterogeneous as established knowledge is rarely integrated into new analyses. Most 
studies test single hypothesis, gathering new correlates of the size of the brain or its parts while ignoring previously established correlations.

(3) Bats are thought to be under strong energetic constraints due to their small body size and the high cost of flight. Knowledge about their high ecological, dietary and morphological diversity in concert with a large published brain data set makes them ideal candidates for such phylogenetic comparative studies. Consequently bats are a good model for our critique of the methodology and robustness of brain size studies with general implications for other taxa.

(4) The lack of availability of appropriate data and overlapping data sets often limits the potential for complex statistical models. Frequently, species" traits remain unknown and phylogenies poorly resolved, although both are indispensable for proper comparative studies. In addition the available data are often biased as specific animal taxa, due to special behavioural and or morphological attributes, receive disproportionate attention.

(5) Finally, we use an example of the correlation between residual testes mass and residual brain mass to show how the inclusion of further variables can influence the outcome of a study. A single bivariate correlation between testes and brain mass loses its statistical significance when a measure for adaptation to habitat complexity (wing area) is included in the model. Our example suggests that in bats these two tissues are not undergoing an energetic trade-off but that other selective pressures such as the neurological demands imposed by the environment may be more important determinants of brain size. More importantly we demonstrate that the interpretation of correlations with brain size can change dramatically if previously established relationships are included.

(6) Comparative studies on brain size will continue to deliver important insights into the evolutionary processes shaping the brain and determining its size. However, future work should include more detailed experimental studies on intra-specific and sex differences, and on regional or seasonal variation to verify the results of published correlations. In addition, the construction of shared data bases of morphological, phylogenetic, and ecological traits, more careful phrasing of hypotheses and the inclusion of the proper variables and methods will enhance the quality of future correlative studies on large data sets, helping us to unravel the evolution of the vertebrate brain.

\section{AGKNOWLEDGEMENTS}

We would like to thank C. Voigt, J. Scharlemann, K. Jones, J. Niven and an anonymous reviewer for valuable comments on the manuscript. K.S. was supported by the SNSF grant PBZHA-118824. D.K.N.D. was supported by a grant of the German Science Foundation (DFG, Vo. 890).

\section{REFERENCES}

Abboty, M. L., Walsi, C. J., Storey, A. E., Strenhoush, I. J., \& HaRLuY, C. W. (1999). Hippocampal volume is related to complexity of nesting habitat in Leach's storm-petrel, a nocturnal Procellariform seabird. Brain Behavior and Evolition 53, 271-276.

ACKERLY, D. D. (2000). Taxon sampling, correlated evolution, and independent contrasts. Erolution 54, 1480-1492.

Aleliso, L. C., BATEs, N. \& Johle, T. H. (200I). In defence of the expensive tissue hypothesis. In Evolutionary anatomy of the primate cerebral cortex (ed. D. Falk and K. R. Gibson), pp. 57-78. Cambridge University Press, Cambridge.

AlEllo, L. C. \& Wieleler, P. (1995). The expensive-lissue hypothesis: the brain and the digestive system in human and primate evolution. Current Anthropology 36 199-221.

Amren, I., Dfchman, D,K.N., Winter, Y. \& LiPp, H. P. (2007). Absent or low rate of adult neurogenesis in the hippoeampus of bats (Chiroptera). PLoS one 2, e455.

Atrwel. D. D. \& Laugulin, S. B. (2001). An energy budget for signaling in the grey matler of the brain. Journal of Cerebral Blood Flow $\mathcal{B}$ Melabolism 21, 1133-1145.

Baron, G. \& Jolicoeur, P. (1980). Brain Siructurc in ChiropteraSome Multivariate Trends. Evolution 34, 386-393.

Baron, T. G., Stephav, H. \& Frailm, H. D. (1996). Comparative Neurobiology in Chiroplera, I edition. Birkhäuser, Basel, Boston, Berlin.

Barraclougi, T. G., Vogler A. P. \& Harvey, P. H. (1998). Revealing the factors that promote speciation. Philosophical Transactions of the Royal Soriety B 353, 241-249.

BARTON, R. A. (1996). Neocortex size and behavioural ecology in primates. Proceedings of the Royal Sociely of London Series B 263, 173-177.

BARTON, R. A. (1998). Visual specialization and brain cvolution in primates. Proceedings of the Royal Society of London B 265, 1933 1937.

BARTON, R. A. (1999). The evolutionary ecology of the primate brain. In Comparative primale socioecology (ed. P.C. Lee). Cambridge University Press, Cambridge.

BARTON, R. A. (2006). Primate brain evolution: Integrating comparative, neurophysiological, and ethological data. Evotutionary Anthropology $15,224-236$.

Barton, R. A. \& HaRvey, P. H. (2000). Mosaic evolution of brain structure in mammals. Nature 405, 1055-1058.

Barion, R. A., Purvis, A. \& Harvey, P. H. (1995). Evolutionary radiation of visual and olfactory brain systems in primates, bats and insectivores. Philosophical Transactions of the Royal Sociely of London Series B 348, 381-392.

Bifgler, R., MeGregor, A., Krfis, J. R. \& Healy, S. D. (2001). A larger hippocampus is associated with longer-lasting spatial memory. Proceedings of the National Academy of Sciences of the United States of America 98, 6941-6944.

BRown, W. M. (2001). Natural selection of mammalian brain components. Trends in Ecology E Evolution 16, 471-473.

Brown, P., Sutrkn, T., Morwood, M. J., Soljono, Jatmiko, SAPromo, E. W. DUE, R. A. (2004). A new small-bodied hominin from the Late Pleistocene of Indonesia. Nabure 431, $1055-1061$

Clark, D. A., Mrtra, P. P. \& WhNo, S.S.-H. (2001). Scalable architecture in mammalian brains. Nature 411, 189-193.

DAy, L. B., WestcotT, D. A. \& Olster, D. H. (2005). Evolution of bower complexity and cercbellum size in bowerbirds. Brain Behavior and Evolution 66, 62-72.

Deaver, R. O., Isler, K., Burkart, J. \& van Schaik, C. (2007). Overall brain size and not encephalization quotient, best predicts cognitive ability across non-human primates. Brain Behavior and Ezolution 70, 115-124 
Desdevises, Y., Legendre, P., A7ou/I, L. \& Morand, S. (2003) Quantifying phylogenctically structured cnvironmental variation. Evoultion 57, 2647-2652.

DE Winter, W. \& OxNard, C. E. (2001), Evolutionary radiations and convergences in the structural organization of mammalian brains. Nalure 409, 710-714.

Dinz-URInRTe, R. \& GarLand, T. (1996). Testing hypotheses of corrclated evolution using phylogenetically independent contrasts: Sensitivity to deviations from Brownian motion. Systematic Biology 45, 27-47.

Diniz-Funo J. A. F, De Sant'ana, C. E. R. \& Bint, L. M. (1998). An cigenvector method for estimating phylogenctic inertia, Evolution 52, 1247-1262.

Dunbat, R. I. M. (1992). Neocortex size as a constraint on groupsize in primates. Fournal of Human Evolution 22, 469 493.

DUNBar, R. I. M. (1995). Neocortex size and group size in primates: a test of the hypothesis. Journal of Ifuman Evolution 28, 287 296.

DuNRar, R. I. M. (1998). The social brain hypothesis. Evolutionary Anthropology 6, 178-190.

Ehmer, B. \& Gronenberg, W. (2004). Mushroom body volumes and visual interncurons in ants: Comparison between sexes and castes. Journal of Comparative Neurology 469, 198-213.

EISENBerG, J. F. \& Wisson, D. E. (1978). Relative brain size and fecding strategies in the Chiroptera. Evolution 32, 740-751.

EMlen, S. T. \& Oring, L. W. (1977), Ecology, sexual selection, and evolution of mating systems. Science 197, 215-223.

Fisenstin, J. (1985). Phylogenies and the comparative method. American Naluralist 125, 1-15.

Fenton, M. B. \& Bocdanowic\%, W. (2002). Relationships between external morphology and foraging behaviour: bats in the genus Myotis. Canadian Journal of Zoology 80, 1004-1013.

Finlay, B. L. \& Darlington, R. B. (1995). Linked regularities in the development and cvolution of mammalian brains. Science 268, 1578-1584.

Fisl, J. L. \& Lockwood, C. A. (2003). Dictary constraints on cncephalization in primates. American Journal of Physical Anthropology 120, $171-181$.

Frlckifion, R. P., Harver, P. H. \& Pagel, M. (2002). Phylogenetic analysis and comparative data: A test and review of evidence. American Naluralist 160, 712-726.

Garamszigi, L. Z., Enns, M., Erritzos, J. \& Moller, A. P. (2005a). Sexually size dimorphic brains and song complexity in passcrinc birds. Behavioral Eology 16, 335 345.

Garamszegr, L. Z., Eens, M., Errit\%ol, J. \& Moller, A. P. (2005b). Sperm competition and sexually size dimorphic brains in birds. Procedings of the Royal Socity $B$ 272, 159-166.

Garland, T, Harvey, P. H. \& Ives, A. R. (1992). Procedures for the analysis of comparative data using phylogenetically independent contrasts. Systematic Biology 41, 18-32.

Grotleman, J. L. \& Kor, M. (1990). Statisties and a null model for estimating phylogenetic effects. Systematic Zoology 39 $227-241$.

Harvey P. H. \& CuUtron-Brock, T. H. (1980). Brain size and ecology in small mammals and primates. Proceedings of the National Academy of Sciences of the United States of America 77, 4387 . 4389.

Harviy, P. H. \& KREBS, J. R. (1990). Comparing brains. Science 249, 140146.

Harvex, P. H. \& PAGEL, M. D. (1991) The comparative method in arolutionary biology. Oxford University Press, Oxford.

HFAL, S. D. \& RowE, C. (2007). A critique of comparative studies of brain size. Proceedings of the Royal Sociely $B 274,453-464$.
Herrera M., L. G., Gutmerriz, E., Hobson, K. A., Altube, B., Diaz, W. G. \& Sánchez-Cordcro, V. (2002). Sources of assimilated protein in five species of New World frugivorous bats. Oecologta 133, 280-287.

Hiadik, C. M., Cunvers, D. J. \& Pasquet, P. (1999). On diet and gut size in non-human primates and humans: Is there a relationship to brain size? Discussion and criticism. Current Anikropology 40, 695-697.

Hoskes, D. J. \& Wirners, P. C. (1997). Temperature regulation and metabolism of an Australian bat, Chalinolobus gouldit (Chiroptera: Vespertilionidae) when euthermic and torpid. Journal of Comparative Physiology B 167, 71-80.

Hu, K. L., Li, Y. X., Gu, X. M., Lh, H. \& ZHang, S. Y. (2006). Brain structures of cholocating and nonecholocating bats, derived in vivo from magnetic resonance images. Nezroreport 17 , $1743-1746$

Hutchion, J. M., Kirsch, J. W. \& Gariand, T. (2002). A comparative analysis of brain size in relation to foraging ecology and phylogeny in the chiroptera. Brain Behavior and Evolution 60, $165-180$.

ISLER, K. \& VAN SCHAIK, C. (2006a). Costs of encephalization: the cnergy trade-of hypothesis tested on birds. Journal of Iluman Evolution 51, 228-243.

ISLER, K. \& VAN SCHAIK, C. P. (2006b). Metabolic costs of brain size cvolution. Biology Lellers 2, 557-560.

Iwaniuk, A. N., Dean, K. M. \& Neuson, J. E. (2004). A mosaic pattern characterizes the evolution of the avian brain. Proceedings of the Royal Society of London Series B 271, S148-S151.

IwANIUK, A. N. \& NELSON, J. E. (2001). A comparative analysis of relative brain size in waterfowl (Anseriformes). Brain Behawior and Evolution 57, 87-97.

Jacobs, L. F., Gauin, S. J. C., Sierre, D. F. \& Hofrman, G. E. (1990). Evolution of spatial cognition - sex-specific patterns of spatial-behavior predict hippocampal size. Proceedings of the National Academy of Sciences of the United Slates of America 87, 6349 6352.

JERison, H. J. (1973). Evolution of the Brain and Intelligence. Academic Press, New York.

JohH, T. H. \& Dunbar, R. I. M. (1997). Visual and socio-cognitive information processing in primate brain evolution. Proceedings of the Royal Sociely of London B 264, 1303-1307.

Jonfs, K. E., Bieiby, J., Cirdillo, M., Fritz S. A., O'Dell, J., Orme, C. D. L., Saft, K., Skchrbst, W., Boakes, H., Carbone, C., Connoliy, C., Cutts, M. J., Foster, K. J., Hakis, M., Plaster, C. A., Price, S. A., Rigby, E. A., Rist, J., Teaciler, A., Bininda-Edmonds, O. R. P., Gittliman, J. L., Mace, G. M. \& PRUvis, A. (submitted). PanTHERIA: A species-level data base of life-history, ecology and geography of extant and recently extinct mammals. Ecology in press.

Jonis, K. E., Bininda-Edmonds, O. R. P. \& GrThlaman, J. L. (2005). Bats, clocks, and rocks: Diversification patterns in chiroptera. Ezolution 59, 2243-2255.

Jonis, K. E., Purvis, A., Maclarnon, A., Bininda-kmonds, O. R. P. \& Simmons, N. B. (2002). A phylogenctic supertree of the bats (Mammalia: Chiroptera). Biological Revietes 77, 223-259.

JONES, K. E. \& MACLARNon, A. M. (2004). Afrording larger brains: Testing hypotheses of mammalian brain evolution on bats. American Naiuralist 164, E20-E3I.

Julan, G. E. \& Groninbero, W. (2002), Reduction of brain volume correlates with behavioral changes in queen anis. Brain Beharior and Exolution 60, 152-164.

KalKo, E. K. V., Handify, C. O. \& Handue, D. (1996). Organization, diversity, and long-term dynamics of a Neotropical 
bat community. In Long-lerm studies of vertebrate communities (ed. M. L. Cody and J. A. Smallwood), pp. 503-553. Academic Press, San Diego.

Kirsch, J. A. W., Fiannery, T. F. \& Springer, M. S. (1995) Phylogeny of the Pteropodidae (Mammalia, Chiroptera) based on DNA hybridization, with evidence for bat monophyly. Austratian Journal of Zoology 43, 395-428.

Krebs, J. R., Sherry, D. F., Healy, S. D., Perry, V. H. \& VAccarino, A. L. (1989). Hippocampal specialization of foodstoring birds. Proceedings of the National Academy of Sciences of the Uniled States of America 86, 1388-1392.

KuNz, T. H. (1982). Roosting ecology of bats. In Ecology of bats (cd. T. H. Kunz), pp 1-55. Plenum Press, New York.

LAPOINTE, F. J., BARON, G. \& LEGENDRE, P. (1999). Encephalization, adaptation and evolution of chiroptera: A statistical analysis with further evidence for bat monophyly. Brain Behavior and Evolution 54, 119-126.

LEwIs, S. E. (1995). Roost fidelity of bats - a review. Journal of Mammalogy 76, 481-496.

LINJENFORS, P. (2005). Neocortex cvolution in primates: the 'social brain' is for females. Biology Letlers 1, 407-410.

Lindenfors, P., Nunn, C. L. \& Barton, R. A. (2007). Primate brain architecture and selection in relation to sex. Bmc Biology 5 .

MADJden, J. (2001). Sex, bowers and brains. Proceedings of the Royal Society of London Series B 268, 833-838.

Maguire, E. A., Gaidin, D. G., Johnsrude, I. S., Good, C. D., Ashburntr, J., Frackowiak, R. S. J. \& Frith, C. D. (2000). Navigation-related structural change in the hippocampi of taxi drivers. Proceedings of the National Academy of Sciences of the United States of America 97, 4398-4403.

MARTIN, R. D. (1981). Relative brain size and basal metabolic-ratc in terrestrial vertebrates. Nalure 293, 57-60.

Marimn, R. D., Genoud, M. \& Hemel.RJj, C. K. (2005). Problems of allometric scaling analysis: Examples from mammalian reproductive biology. Fournal of Experimental Biology 208, 1731-1747.

Martins, E. P. \& Hansen, T. F. (1999). Phylogenies and the comparative method: a general approach to incorporating phylogenetic information into the analysis of interspecific data. American Naluralist 153, 448-448.

MCNAB, B. K. (1969). The economics of temperature regulation in Ncotropical bats. Comparative Biochemistry and Physiology, 227-268.

MGNAB, B. K. (2003). Standard energetics of phyllostomid bats: the inadequacies of phylogenetic-contrast analyses. Comparative Biochemislry and Physiology a-Molecular É Integrative Physiology 135, 357-368.

McNAB, B. K. \& EISENBERG, J. F. (1989). Brain size and its relation to the rate of metabolism in mammals. American Naluralist 133, 157-167.

MINDELL, D. P. (1991). Phylogenetic-relationships among megabats, microbats, and primates. Proceedings of the National Academy of Sciences of the Uniled States of America 88, 10322-10326.

NIISSON, G. E. (1996). Brain and body oxygen requirements of Gnalhonemus pelersii, a fish with an exceptionally large brain. Journal of Experimental Biology 199, 603-607.

NivEN, J. E. (1996). Brain and body oxygen requirements of Gnathonemus pelersii, a fish with exceptionally large brain. Journal of experimenlal Biology 199, 603-607.

NIven, J. E. (2005). Brain evolution: Getting better all the time? Current Biology 15, R624-R626.

NIVEN, J. E. (2007). Brains, islands and evolution: breaking all the rules. Trends in Ecology \& Evolution 22, 57-59.
Niven, J. E., Anderson, J. C. \& Laughiln, S. B. (2007). Fly photoreceptors demonstrate energy-information trade-offs in neural coding. PLoS Biology 5, 828-840.

Niven, J. E. \& Laugilun, S. B. (2008). Energy limitation as a selective pressure on the evolution of sensory systems. Journal of experimental Biology 211, 1792-1804.

Niven, J. E., Vhhasoyrinki, M. \& Juusola, M. (2003). Shaker K1channels are predicted to reduce the metabolic cost of neural information in Drosophila photoreceptors. Proceedings of the Royal Sociely of London Series B-Biological Sciences 270, S58-S6I.

NorberG, U. M. \& RaYnkR, J. M. V. (1987). Ecological morphology and flight in bats (Mammalia, Chiroptera) - wing adaptations, light performance, foraging strategy and echolocation. Philosophical Transactions of the Royal Sociely of London B 316, 337-419.

Nownk, M. R. (1994). Walker's bats of the world. Johns Hopkins University Press, London.

PaGe, R. A. \& Ryan, M. J. (2006). Social transmission of novel foraging behavior in bats: Frog calls and their referents. Current Biology 16, 1201-1205.

PAGEL, M. (1994). Detecting correlated cvolution on phylogenies: a general method for the comparative analysis of discrete characters. Proceedings of the Royal Society of London Series B 255, 37-45.

PAGEL, M. (1997). Inferring evolutionary prccesses from phylogenies. Zoologica Scripla 26, 331-348.

PAGEL, M. (1999a). Inferring the historical patterns of biological cvolution. Nature 401, 877-884.

PAGEl, M. (1999b). The maximum likelhood approach to reconstructing ancestral character states of discrete characters on phylogenies. Systemalic Biology 48, 612-622.

Pérez-Barberia, F. J., Shlultz, S. \& Dunbar, R. I. M. (2007). Evidence for coevolution of sociality and relative brain size in three orders of mammals. Evolution 61, 2811-2821.

Paitigrew, J. D. (1986). Flying primates? Megabats have the advanced pathway from eye to midbrain. Science 231, 1304 1306.

Pettigrew, J. D., Jamieson, B. G. M., Robson, S. K., Hall, L. S., McAnally, K. I. \& Cooper, H. M. (1989). Phylogenetic relations between microbats, megabats and primates (Mammalia: Chiroptera and Primates). Philosophical Transaclions of the Royal Sociely of London B 325, 489-559.

Pettigrew, J. D. \& Kirsch, J. A. W. (1998). Base-compositional biases and the bat problem: I. DNA-hybridization melting curves based on AT- and GC-enriched tracers. Philosophical Transaclions of the Royal Society of London B 353, 369-379.

Pirlot, P. \& Stepiav, H. (1970). Encephalization in Chiroptera. Canadian Journal of Zoology 48, 433-444.

Pitnick, S., Jonks, K. E. \& Wilkinson, G. S. (2006). Mating system and brain size in bats. Proceedings of the Royal Sociely B 273, 719-724.

Pravosudov, V. V., Lavenex, P. \& Clayton, N. S. (2002). Changes in spatial memory mediated by experimental variation in food supply do not affect hippocampal anatomy in mountain chickadees (Poecile gambeli). Journal of Neurobiology 51, 142-148.

R Development Core Team (2008). R: a language and environment for statistical computing. $R$ Foundation for Stalistical Computing. Vienna, Austria. ISBN 3-900051-07-0.

Racey, P. A. \& Speakman, J. R. (1987). The energy costs of pregnancy and lactation in heterothermic bats. In Symposia of the Zoological Society of London no. 57, pp. 107-125. 
Ratchifte, J. M. \& Fenton, M. B. \& Shettleworth, S. J. (2006). Behavioural Aexibility positively correlated with relative brain volume in predatory bats. Brain Behavior and Evolution 67, 165-176.

RAiciJFF, J. M. \& 'THR Hofstede, H. M. (2005), Roosts as information centres: social learning of food preferences in bats. Biology Lellers 1, 72-74.

READER, S. M. \& LALAvD, K. N. (2002). Social intelligence, innovation, and cnhanced brain size in primates. Froceedings of the National Academy of Science USA 99, 4436-4441.

Rraoreda, J. C., Glayton, N. S. \& Kacel niK, A. (1996). Species and sex differences in hippocampus size in parasitic and nonparasitic cowbirds. Neuroreport 7, 505-508.

Rome, $G$ \& Dicke, U. (2005). Evolution of the brain and intelligence. Trends in Cognitive Sciences 9, 250-257.

SAF, K. \& DECHMANN, D. K. N. (2005). Adaptation of brain regions to habitat complexity: a comparative analysis in bats (Chiroptera). Proceedings of the Roval Society B 272, 179-186.

Saf, K., Sfid, M. A. \& Drchmann, D. K. N. (2005). Bigger is not always better: when brains get smaller. Biology Letters 1, 283-286.

SAunders, M. B. \& Barclay, R. M. R. (1992). Ecomorphology of inscctivorous bats - a test of predictions using 2 morphologically similar species. Ecology 73, 1335-1345.

Scinttzler, H. U., Moss, G. F. \& Denzinger, A. (2003). From spatial orientation to food acquisition in echolocating bats. Trends in Ecology 80 Evolution 18, 386-394.

SilerRy, D. F, Forbes, M. R. L., KhURGal, M. \& IVY, G. O. (1993). Females have a larger hippocampus than males $\mathrm{n}$ the broodparasitic brown-headed cowbird. Proceedings of the National Academy of Sciences USA 90, 7839-7843.

Silultz, S., Bradbury, R. B., Evans, K. L., Gregory, R. D. \& BLACKBURN, T. M. (2005). Brain size and resource specialization predict long-term population trends in British birds. Proceedings of the Royal Society B 272, 2305-2311.

SIJUi:T/, S. \& DUNBAR, R. I. M. (2006). Both social and ecological factors predict ungulate brain size. Procedings of the Royal Society $B$ $273,207-215$.

Sifmers, B. M. \& ScinvizLeR, H.-U. (2004). Echolocation signals reflect niche differentiation in five sympatric congeneric bat specics. Nature 429, 657-661.
SOl, D., Sziken, T., LiKer, A. \& LEFEbVRE, L. (2006). Big-braincd birds survive better in nature. Journal of Omilhology 147, 254-254.

Staniope, M. J., Czedusniak, J., Sl, J.-S., Nickerson, J. \& Goodman, M. (1992). A molecular perspective on mammalian evolution from the gene encoding interphotoreceptor retinoid binding protein, with convincing evidence for bat monophyly Molecular Phylogenetics and Evolution 1, 148-160.

Strifoter, G. F. (2005). Principles of Brain Evolution. Sinauer Associates, Inc., Sunderland, Massachusetts.

Srmonds, M. R. E. (2002). The effects of topolgical inaccuracy in evolutionary trees on the phylogenetic comparative method of independent contrasts. Systematic Biology 51, 541-553.

Srmonds, M. R. E. \& ELCaR, M. A. (2002). Phylogeny affects estimation of metabolic scaling in mammals. Evolution 56,2330 2333.

TAYLoR, A. B., \& VAN SCHAK, C. (2007), Variation in brain size and ecology in Pongo. Journal of Human Ezolution 52, 59-71.

Trelung, E. C., Scally, M., KaO, D. J., Romagnoli, M. L., Springer, M. S. \& Stanhope, M. J. (2000). Molecular cvidence regarding the origin of ccholocation and llight in bats. Nature 403, 188-192.

TuEWISSEN, J. G. M. \& BABCOCK, S. K. (1991). Distinctive cranial and cervical innervation of wing museles - new evidence for bat monophyly. Science 251, 934-936.

Ulanovsky, N. \& Moss, C. F. (2007). Hippocampal cellular and network activity in freely moving echolocating bats. Nalure Neuroscience 10, 224-233.

Votct, G. C. \& Winter, Y. (1999). Energetic cost of hovering light in nectar-feeding bats (Phyllostomidae: Glossophaginac) and its scaling in moths, birds and bats. Fournal of Comparative Physiology $B$ $169,38-48$.

Wuderman, L., RutLedge, J. N. \& Bigler, E. D. (1991). In-vivo brain and intelligence. Intelligence 15, 223-228.

WINTER, Y. (1998). Energetic cost of hovering flight in a nectarfeeding bat measured with fast-response respirometry. Journal of Comparative Physiology B 168, 434-444.

Wirelson, S. F., BerFSH, H. \& KIGAR, D. L. (2006). Intelligence and brain size in 100 postmortem brains: sex, lateralization and age factors. Brain 129, 386-398. 